\title{
Viabilidad del préstamo interbibliotecario como medio para crear una red de préstamo a domicilio en el subsistema de humanidades de la Universidad Nacional Autónoma de México
}

Viability of interlibrary loan as a background for creating a network of domicile loan in the subsystem of humanities of the Universidad Nacional Autónoma de Mexico

\section{María de los Angeles Ciprés Oliva, Reyna Carolina González García, Juan Antonio Hernández Mendoza y María Magdalena Miranda Díaz}

Biblioteca del Instituto de Investigaciones Filológicas de la UNAM, Circuito Mario de la Cueva s/n, Ciudad Universitaria C.P. 04510 Del. Coyoacán, México, D.F. acipres@servidor.unam.mx, carogoga@servidor.unam.mx

\section{Resumen}

Se analiza el préstamo interbibliotecario en las bibliotecas del Subsistema de Humanidades de la Universidad Nacional Autónoma de México (UNAM), para lograr establecer el préstamo a domicilio entre estas bibliotecas. Se utilizó la observación directa y la aplicación de cuestionarios a los encargados de las bibliotecas del Subsistema. Las bibliotecas del Subsistema solicitan en mayor porcentaje préstamos interbibliotecarios entre las bibliotecas pertenecientes al mismo Subsistema. Es posible eliminar el servicio de préstamo interbibliotecario y establecer una credencial única que permita el acceso al préstamo a domicilio de su material bibliográfico a cada usuario que está registrado en alguna dependencia del Subsistema. Se recomienda Iniciar una red con la participación de por lo menos dos bibliotecas, permitiendo que poco a poco se incorporen las demás bibliotecas, y crear esta red con el propósito de que a futuro se pueda establecer una cooperación bibliotecaria que permita el compartimiento de acervos y recursos.

Palabras clave: Disponibilidad de libros. Colaboración interbibliotecaria. Biblioteca. Circulación. Préstamos. Préstamos interbibiliotecarios.

\section{Introducción}

La presente investigación surgió a partir del análisis de la dinámica del préstamo interbibliotecario del año 2006 en la biblioteca "Rubén Bonifaz Nuño" del Instituto de Investigaciones Filológicas de la UNAM; en ella nos dimos cuenta que la mayor cantidad de los préstamo solicitados a dicha biblioteca proviene de bibliotecas

\begin{abstract}
The interlibrary lending in the libraries belonging to the UNAM's Subsystem of Humanities is analyzed with the aim of establishing domicile lending. Direct observations were made and questionnaires were applied to the responsible of the libraries of the UNAM's Humanities Subsystem. Most of the interlibrary lending of each library is done between the other libraries belonging to the subsystem. It is possible to eliminate the interlibrary lending and establish a single credential that allows the access to domicile lending of the bibliographic material from the libraries subsystem to each user registered on any of the dependencies of the subsystem. It is recommended that a network is started with at least two libraries, allowing others to incorporate in the future; and that this network is created with the purpose that in the future it will be possible to establish a cooperation that will allow them to share assets and resources.
\end{abstract}

Keywords: Books availability. Interlibrary cooperation. Libraries. Circulation. Library loan. Interlibrary loan.

como las del Instituto de Investigaciones Filosóficas, Instituto de Investigaciones Sociales, Instituto de Investigaciones Estéticas, Instituto de Investigaciones Históricas, Facultad de Filosofía y Letras, Facultad de Ciencias Políticas y Sociales y Colegio de México. Esta situación nos permitió ver que, por la especialidad de dichas bibliotecas, el servicio de préstamo interbibliotecario era (y es hasta la fecha) el más solicitado 
por las bibliotecas que forman parte del Subsistema de Humanidades de la UNAM. De aquí surgió la inquietud de saber si entre estas bibliotecas que conforman el subsistema, es posible eliminar el trámite del préstamo interbibliotecario y que los usuarios tuvieran la oportunidad de solicitar a cualquiera de ellas su préstamo a domicilio, utilizando una credencial única que acredite dicho préstamo en todas y cada una de las bibliotecas del subsistema y así evitar que el usuario acuda a su biblioteca a pedir el formato del préstamo interbibliotecario; igualmente, la biblioteca podría eliminar el apoyo de servicio de mensajería para este servicio. Para esto consideramos necesario conocer la dinámica del préstamo interbibliotecario en las demás bibliotecas de este subsistema.

Con relación a nuestra propuesta en el mes de junio de 1991 se reunió el Consejo del Sistema Bibliotecario de la UNAM, está reunión estuvo presidida por el Sr. Rector Dr. José Sarukhán, y de 15 a 23 miembros que lo integraban. El Mtro. Adolfo Rodríguez Gallardo, Director General de Bibliotecas, en su carácter de secretario del Consejo, presentó siete temas a la consideración del mismo, de acuerdo con los proyectos establecidos en el Reglamento General del Sistema Bibliotecario. En primer lugar abordó el tema la "Viabilidad de la instrumentación de la credencial única en el Sistema", acordando el Consejo que los usuarios universitarios, estudiantes de bachillerato, licenciatura y posgrado, así como el personal académico y administrativo, pudieran disfrutar de los servicios bibliotecarios con la presentación de la credencial que la institución expide a cada uno de ellos, atendiendo siempre a sus reglamentos internos. Los demás proyectos estaban encaminados al apoyo del primer tema, esto fue: la viabilidad y pertinencia de establecer un procedimiento único de control de la circulación de los acervos del sistema; extensión y generalización de los apoyos informáticos del sistema; plan de formación, capacitación y desarrollo profesional del personal bibliotecario; y establecimiento de las comisiones y elaboración de los reglamentos de bibliotecas, Establecimiento del Comité del Consejo del Sistema Bibliotecario y Plan Anual de Desarrollo Bibliotecario de la UNAM (Molina, 1991). En dicha reunión se manifestó la existencia de una credencial única para el préstamo a domicilio en las bibliotecas de la UNAM; ahora consideramos que esta opción es viable porque prescinde del trámite de préstamo interbibliotecario únicamente entre las bibliotecas del Subsistema de Humanidades de la UNAM.

Por todo lo expuesto anteriormente, iniciamos esta investigación, con el objetivo de analizar el préstamo interbibliotecario en las bibliotecas del Subsistema de Humanidades de la UNAM para lograr establecer el préstamo a domicilio entre estas bibliotecas.

Para cumplir con el objetivo planteado, el presente trabajo se estructuró en nueve apartados. La primera parte contiene la introducción. La segunda parte desarrolla la metodología utilizada para llevar a cabo el estudio. La tercera parte da a conocer, como marco de referencia, las bibliotecas del Subsistema de Humanidades, describiendo el contexto general sobre su importancia, sus acervos, la función del comité de biblioteca, reglamento e infraestructura de cómputo, a fin de tener un margen de descripción. La cuarta parte expone el préstamo interbibliotecario, mostrando un contexto general. La quinta parte explica los resultados que se obtuvieron en este estudio. La sexta parte expone la discusión de los resultados. La séptima parte presenta las conclusiones. Por último, se muestran las recomendaciones y las referencias, así como los apéndices que consisten en el cuestionario aplicado a los coordinadores de las bibliotecas especializadas del Subsistema de Humanidades de la UNAM y las gráficas con los resultados obtenidos.

\section{Metodología}

Para cumplir con el objetivo planteado al inicio de este estudio, se consideró apropiado aplicar la metodología siguiente:

- El primer método utilizado fue el análisis de la información contenida en las fuentes bibliohemerográficas relacionadas con los siguientes temas: el préstamo interbibliotecario, para conocer lo que actualmente se ha realizado con este servicio en las bibliotecas del mundo; y las bibliotecas del Subsistema de Humanidades de la UNAM, para conocer la especialidad de cada una de ellas.

- Por ser una investigación descriptiva, se utilizaron las técnicas de cuestionario, entrevista y observación directa, las cuales fueron aplicadas a los coordinadores de las bibliotecas especializadas del Subsistema de Humanidades de la UNAM, para conocer su punto de vista acerca del servicio de préstamo interbibliotecario y de esta manera enterarnos de la situación de este servicio en las bibliotecas.

Es importante mencionar que, debido a que el cuestionario tiene una cantidad pequeña de preguntas, el recuento y la decodificación de las respuestas obtenidas se realizó de forma manual y sólo se requirió de medios automatizados para graficar y presentar los resultados. 
Debido a la dificultad que representaba encuestar a las 20 bibliotecas del Subsistema de Humanidades de la UNAM, se prefirió visitar las bibliotecas localizadas en el campus central de la Ciudad Universitaria, ya que con ellas se tiene una mayor comunicación en lo que a préstamo interbibliotecario se refiere, por lo que fueron idóneas para obtener la información que requeriamos.

Las bibliotecas del Subsistema de Humanidades que se localizan en la Ciudad Universitaria son las siguientes:

- Biblioteca del Centro Coordinador y Difusor de Estudios Latinoamericanos (CCYDEL)

- Biblioteca del Centro de Investigaciones Interdisciplinarias en Ciencias y Humanidades (CEIICH)

- Biblioteca del Centro de Enseñanza de Lenguas Extranjeras (CELE)

- Biblioteca del Centro de Enseñanza para Extranjeros (CEPE) campus Ciudad Universitaria

- Biblioteca del Centro de Investigaciones sobre América del Norte (CISAN)

- Biblioteca del Centro Universitario de Investigaciones Bibliotecológicas (CUIB)

- Biblioteca del Instituto de Investigaciones Antropológicas (IIA)

- Biblioteca del Instituto Investigaciones Económicas (IIEc)

- Biblioteca del Instituto de Investigaciones Estéticas (IIE)

- Biblioteca del Instituto de Investigaciones Filológicas (IIFL)

- Biblioteca del Instituto de Investigaciones Filosóficas (IIF)

- Biblioteca del Instituto de Investigaciones Históricas (IIH)

- Biblioteca del Instituto de Investigaciones Jurídicas (IIJU)

- Biblioteca del Instituto de Investigaciones Sociales (IIS)

- Biblioteca del Instituto de investigaciones Sobre la Universidad y la Educación (IISUE)

- Biblioteca del Programa Universitario de Estudios de Género (PUEG)

\subsection{Los cuestionarios-entrevista}

La técnica de campo básica que se utilizó fue la del cuestionario, y para cumplir con su propósito en esta investigación el cuestionario aplicado tuvo las siguientes características:

- Fue aplicado personalmente bajo la modalidad de entrevista, con el objeto de que la observación directa complementara la información verbal proporcionada por los encuestados.

- Tuvo un formato preestablecido.

- Debido a que se requerían algunas opiniones y sugerencias de los encuestados, y tomando en cuenta que este tipo de información es difícil de codificar en opciones, en los cuestionarios se incluyeron preguntas abiertas o no estructuradas, que son aquellas que "permiten a los encuestados contestar libremente sin tener que seleccionar una de varias respuestas proporcionadas" (Busha, 1990, p. 72).

- Se incluyen preguntas sobre opinión y actitud para conocer el punto de vista de los encuestados sobre el servicio de préstamo interbibliotecario.

\subsection{La aplicación de los cuestionarios.}

Las bibliotecas fueron elegidas tomando como fuente básica el Directorio del Sistema Bibliotecario de la UNAM.

Con respecto al horario y a los días de la semana en que se aplicaron los cuestionarios, debemos decir que se llevó a cabo por la mañana, de lunes a viernes, tomando en cuenta que había mayor posibilidad de localizar a los coordinadores. Cabe mencionar que esta actividad se realizó durante mes y medio.

\section{Bibliotecas del Subsistema de Humanidades de la UNAM}

Las labores más importantes del quehacer universitario son la investigación, la docencia, la preservación y difusión del conocimiento. La UNAM, a través del Subsistema de Humanidades, apoya a estudiantes, cuerpo docente e investigadores hacia la adquisición de verdaderos conocimientos significativos, es decir, aprendizajes críticos que fomenten una visión orientada a construir nuevos modos de vida, fundamentando, con ello, la pluralidad, el respeto, la diversidad y la tolerancia, siempre desde una racionalidad humanista. Así, la UNAM permite que el estudiante universitario, no importa el nivel en el que se encuentre, asuma un compromiso mayor con su materia de estudio y favorezca a su mejor desempeño como persona y como individuo competente, capaz de expresar sensibilidad, ética y estética y, sobre todo, que contribuya como ciudadano participativo en el desarrollo de nuestro país. 
En este contexto, las bibliotecas especializadas del Subsistema de Humanidades de la UNAM contribuyen, de manera destacada, para que los profesionales de las humanidades cuenten con los recursos y servicios de información que apoyan la formación académica y el desarrollo de la investigación.

De acuerdo a la Dirección General de Bibliotecas de la UNAM, el Subsistema de Humanidades campus Ciudad Universitaria cuenta con 16 bibliotecas, de las cuales seis pertenecen a Centros como el de Coordinador y Difusor de Estudios Latinoamericanos (CCYDEL), el de Investigaciones Interdisciplinarias en Ciencias y Humanidades (CEIICH), el de Enseñanza de Lenguas Extranjeras (CELE), el de Enseñanza para Extranjeros (CEPE) campus Ciudad Universitaria, el de Centro de Investigaciones sobre América del Norte (CISAN) y el de Universitario de Investigaciones Biblotecológicas (CUIB); otras nueve corresponden a los Institutos de Investigaciones Antropológicas (IIA), Económicas (IIEc), Estéticas (IIE), Filológicas (IIFL), Filosóficas (IIF), Históricas (IIH), Jurídicas (IIJU), Sociales (IIS), Sobre la Universidad y la Educación (IISUE); y una más perteneciente al Programa Universitario de Estudios de Género (PUEG).

El Subsistema de Humanidades a través de estas bibliotecas conserva y resguarda los estudios y conocimientos de las ciencias humanas, tales como la antropología, la filología, la historia y la filosofía, entre otras como se puede leer a continuación:

La Biblioteca del Centro Coordinador y Difusor de Estudios Latinoamericanos abarca un acervo especializado en historia, literatura, filosofía, historia de las ideas y ciencias políticas y sociales de la región.

La Biblioteca del Centro de Investigaciones Interdisciplinarias en Ciencias y Humanidades contiene un acervo especializado en proyectos interdisciplinarios en el campo de las Ciencias y las Humanidades.

La Biblioteca del Centro de Enseñanza de Lenguas Extranjeras contiene un acervo especializado en material para la enseñanza de lenguas y sobre lingüística aplicada.

La Biblioteca del Centro de Enseñanza para Extranjeros tiene un acervo especializado en enseñanza del español como segunda lengua; arte, historia, literatura de México e Hispanoamérica y estudios chicanos.

La Biblioteca del Centro de Investigaciones sobre América del Norte posee un acervo especializado sobre la región de América del Norte. Así como también reúne estudios de los temas relacionados con el proceso de integración de México con Estados Unidos y Canadá, además de otras regiones comerciales del mundo.

La Biblioteca del Centro Universitario de Investigaciones Bibliotecológicas conserva un acervo especializado en bibliotecología, estudios de la información y en general en las Ciencias de la Información.

La Biblioteca del Instituto de Investigaciones Antropológicas conserva un acervo especializado en antropología física, arqueología, etnología, antropología social y lingüística antropológica.

La Biblioteca del Instituto de Investigaciones Económicas tiene un acervo especializado en economía mundial, economía industrial, economía del sector primario, economía urbana y regional, economía aplicada, economía del trabajo y de la tecnología, historia económica, economía fiscal y financiera, economía de la educación, la ciencia y la tecnología, economía del sector energético, economía política del desarrollo, estudios hacendarios y del sector público.

La Biblioteca del Instituto de Investigaciones Estéticas posee un acervo especializado en historia del arte, arte mexicano (prehispánico, colonial, moderno y contemporáneo) y estética.

La Biblioteca del Instituto de Investigaciones Filológicas abarca un acervo especializado en lenguas y literaturas grecolatinas, hispánicas y amerindias; filología, lingüística, gramática, lexicología, morfología, fonética, poética, civilización y cultura grecorromana, medieval y maya.

La Biblioteca del Instituto de Investigaciones Filosóficas conserva un acervo especializado en lógica, epistemología, filosofía de la ciencia, filosofía del lenguaje, filosofía de la mente, ética, filosofía, política, filosofía del derecho, historia de la filosofía, ontología y metafísica, filosofía de la religión, filosofía en México y estética.

La Biblioteca del Instituto de Investigaciones Históricas conserva un acervo especializado en Historia de México, abarcando desde el período prehispánico hasta la época contemporánea, así como materiales referentes a la historia de América Latina, Europa y Estados Unidos.

La Biblioteca del Instituto de Investigaciones Jurídicas contiene un acervo especializado en derecho.

La Biblioteca del Instituto de Investigaciones Sociales posee un acervo especializado en estudios agrarios, población y estudios demográficos, estudios urbanos y regionales, gobierno, 
procesos y actores sociales, historia social y política, estudios de la educación y la ciencia, sociología de los procesos políticos, sociolingüística y cultura.

La Biblioteca del Instituto de Investigaciones Sobre la Universidad y la Educación reúne un acervo especializado en educación superior y universidad contemporánea, problemas de la educación en sus diferentes modalidades y niveles, e historia de las instituciones, en particular las universitarias y los colegios, así como historia de la educación.

La Biblioteca del Programa Universitario de Estudios de Género tiene un acervo especializado en estudios de género, migración, justicia, identidad, interculturalidad y los derechos humanos.

Estas bibliotecas especializadas tienen como objetivo principal apoyar con servicios de información documental a los investigadores, docentes, técnicos académicos, estudiantes y público en general, en apoyo a la investigación, la docencia y la difusión de la especialidad.

También tienen como función principal seleccionar, adquirir, organizar, conservar y difundir el material documental, así como brindar los servicios propios de la biblioteca en forma oportuna y eficaz. Fomentar el intercambio y la colaboración entre los diferentes Centros e Institutos y bibliotecas afines, estableciendo firmas de convenios.

Las bibliotecas del Subsistema para lograr satisfactoriamente sus metas y compromisos, cuentan con el apoyo de una Comisión de Biblioteca (conforme a los artículos 18 al 20 del Reglamento General de Servicios Bibliotecarios de la UNAM), la cual está integrada por el Director del Centro o Instituto, el Secretario Académico, el Secretario Técnico, el Coordinador de la Biblioteca, investigadores del Centro o Instituto, y dos miembros del personal académico y administrativo de la biblioteca. Dicha Comisión tiene las siguientes funciones:

1. Auxiliar al titular de la dependencia, al consejo técnico, interno o asesor y al responsable o encargado de la biblioteca.

2. Opinar sobre las políticas de desarrollo y crecimiento de la biblioteca.

3. Colaborar en las tareas de diseño, operación y evaluación de los servicios bibliotecarios y vigilar su aplicación.

4. Seleccionar el material documental, a partir de las bibliografías básicas, y hacérselo llegar al personal académico y demás usuarios.
5. Asegurar que las publicaciones que edita la dependencia se encuentren en su biblioteca.

6. Prever sobre las necesidades presupuestarias de la biblioteca para adquisición del material documental, compra de mobiliario y equipo especializado.

7. Opinar sobre las necesidades del personal que labora en las bibliotecas y la ampliación de espacios y servicios.

8. Coadyuvar en la vigilancia de los recursos destinados a la biblioteca, a fin de que éstos sean utilizados para los fines a los cuales fueron asignados.

9. Presentar al consejo técnico o interno y asesor o titulares de las dependencias que no cuenten con ellos, los reglamentos internos de la biblioteca y de la propia Comisión, así como las modificaciones a los mismos.

10.Determinar las medidas generales para garantizar los servicios mencionados en el artículo 17 del Reglamento General del Sistema Bibliotecario de la UNAM.

11. Conocer y vigilar los planes de capacitación, formación y desarrollo profesional del personal bibliotecario.

12. Las demás que se desprenden de su naturaleza y las que le confiera la legislación Universitaria.

En cada sesión de la Comisión de Biblioteca se levanta el acta correspondiente, en la cual deben quedar asentados los detalles de la misma así como los acuerdos de cada sesión. Se pueden convocar reuniones extraordinarias de la Comisión de Biblioteca a petición del titular de la dependencia o por su representante en la comisión, o bien por un tercio de los integrantes de la misma, con objeto de discutir asuntos urgentes relacionados con la biblioteca y su desarrollo.

Con el propósito de salvaguardar su información documental, cada una de las bibliotecas del Subsistema cuenta con su propio reglamento, en el que se especifican los servicios que proporcionan y los derechos y obligaciones de los usuarios. Reglamento que se establece conforme a los principios del Reglamento General del Sistema Bibliotecario de la UNAM y a las características generales que establezca la Dirección General de Bibliotecas.

Es importante mencionar que cada una de las bibliotecas del Subsistema cuenta con la infraestructura de cómputo necesaria para ofrecer servicios y garantizar el funcionamiento de las diferentes actividades bibliotecarias. 


\section{El préstamo interbibliotecario}

Actualmente el crecimiento de la información hace que todo el mundo tenga la necesidad de un mayor y mejor intercambio de información documental entre bibliotecas, centros de documentación y unidades de información. Esto se debe a que la información, muchas veces dispersa en varios documentos, se vuelve inalcanzable en una biblioteca sin los recursos económicos suficientes para poder adquirir todos los documentos, aunado a que las bibliotecas generalmente no cuentan con el espacio físico necesario para albergar toda la información que requieren sus usuarios. Esto hace que las bibliotecas no tengan otra alternativa más que la cooperación interbibliotecaria para compartir recursos como el acceso bibliográfico, el préstamo interbibliotecario y el desarrollo cooperativo de colecciones.

Para las bibliotecas es de vital importancia el servicio de préstamo interbibliotecario, pues permite obtener información que se encuentra en el acervo de otras bibliotecas, facilitando así el préstamo mutuo del material documental y respetando un convenio de cooperación siempre en términos de equidad, reciprocidad y respeto a las políticas de cada uno de los miembros con el propósito principal de satisfacer las necesidades de información de sus usuarios.

En este contexto actualmente existen grupos de bibliotecas o consorcios de cooperación interbibliotecaria con el propósito de mejorar los servicios y de reducir costos; por ejemplo, en México una de las redes más conocidas es la del "Grupo Amigos", que es la Red de Cooperación México-Estados Unidos, creada para facilitar el préstamo de libros, material microfilmado y artículos de revistas entre algunas bibliotecas de ambos países.

En nuestro país, y en específico en nuestra casa de estudios, la continúa demanda de información por parte de investigadores, cuerpo docente y estudiantes de la UNAM, al igual que un presupuesto limitado, son dos factores que han propiciado a que las bibliotecas de la UNAM utilicen el servicio de préstamo interbibliotecario como uno de sus principales servicios y de esta manera exista una cooperación interbibliotecaria a nivel local; y por qué no, a nivel internacional.

\section{Resultados}

Luego de conocer algunos de los detalles de las bibliotecas del Subsistema de Humanidades de la UNAM y del servicio de préstamo interbibliotecario, vamos a hablar de la situación de este servicio en las bibliotecas del Subsistema.



Préstamo interbibliotecario con apoyo del servicio de mensajería: $100 \%$

Figura 1. Bibliotecas en las que el servicio de préstamo interbibliotecario es apoyado por el servicio de mensajería.

Como se puede observar, la Figura 1 nos muestra el porcentaje de las bibliotecas en las que el servicio de préstamo interbibliotecario cuenta con el apoyo del servicio de mensajería. En este caso podemos ver que todas las bibliotecas cuentan con dicho apoyo, lo cual ha permitido a sus usuarios obtener en su propia biblioteca los documentos localizados en otras, y de esta manera se facilita el acceso a la información. Con respecto a esto observamos que el apoyo del servicio de mensajería es otorgado por la Unidad Administrativa de los Centros e Institutos; sin embargo la mayoría de las bibliotecas utilizan este servicio únicamente para los documentos solicitados por investigadores, lo que significa que los demás usuarios tienen que trasladarse a las otras bibliotecas para solicitar y recoger su material. Algunos coordinadores de estas bibliotecas comentan que el apoyo de mensajería cuenta con dos desventajas. La primera es que los investigadores obtienen su documento uno o dos días después del día solicitado; en tal caso, si el documento se encuentra en las bibliotecas del campus de Ciudad Universitaria, lo obtienen tal vez el mismo día o un día después y si se localiza en bibliotecas foráneas, o de otras instituciones tardan uno o dos días más. La segunda desventaja es que los investigadores tienden a devolver este material a su biblioteca justamente el día que se vence la fecha de préstamo, ocasionando que mensajería devuelva con un día o dos de retraso.

Además comentan que el apoyo de mensajería es aceptado aun cuando los investigadores muestren urgencia y pocas posibilidades de espera en el tiempo de entrega, lo cual hace que mensajería entregue lo más rápido posible el material. 


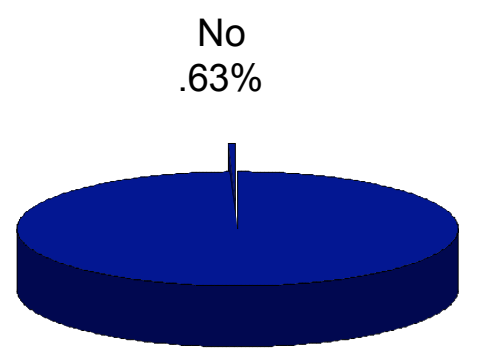

$\mathrm{Si}$

$99.37 \%$

Figura 2. Nivel de aceptación del servicio de mensajería por parte de lo usuarios.

En la Figura 2 podemos ver que todos los investigadores aceptan que su préstamo interbibliotecario sea traído a su biblioteca por medio del servicio de mensajería; este resultado se interpreta como, un servicio satisfactoriamente funcional y en caso de que los investigadores requieran su material con urgencia, se notifica al servicio de mensajería y se envía por la obra lo más pronto posible. Al respecto, observamos que este servicio evita que los investigadores pierdan tiempo en trasladarse a otras bibliotecas fuera de la UNAM o para aquellas que están retiradas de su propia biblioteca. En el caso de las bibliotecas del Subsistema de Humanidades podemos ver que tienden a necesitar material de las otras bibliotecas del mismo Subsistema y que por lo menos nueve de éstas se encuentran ubicadas una al lado de otra y aun así se utiliza el servicio de mensajería. Esto más que agilizar la obtención del documento, indica que el investigador prefiere aprovechar el servicio aunque le signifique la tardanza del material.

En la Figura 3 y 4 se puede observar que todas las bibliotecas realizan consultas telefónicas para confirmar la disponibilidad del material bibliográfico en otras bibliotecas, lo cual es necesario pues en algunas ocasiones el documento podría estar en préstamo, encuadernación o en proceso técnico; igualmente realizan la reservación de los documentos, agilizando así la obtención de los documentos.

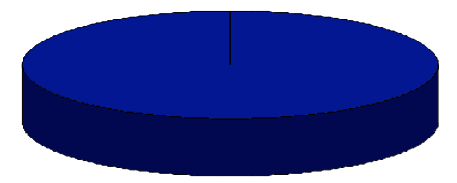

Bibliotecas que confirman la disponibilidad del material: $100 \%$

Figura 3. Bibliotecas que confirman la disponibilidad del material en otras bibliotecas.

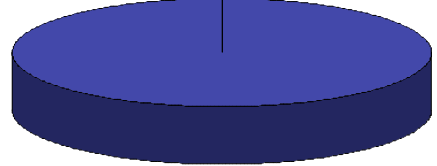

Bibliotecas que reservan material solicitado en préstamo interbibliotecario: $100 \%$

Figura 4. Bibliotecas que ofrecen a otras bibliotecas la reservación del material que solicitan en préstamo interbibliotecario.

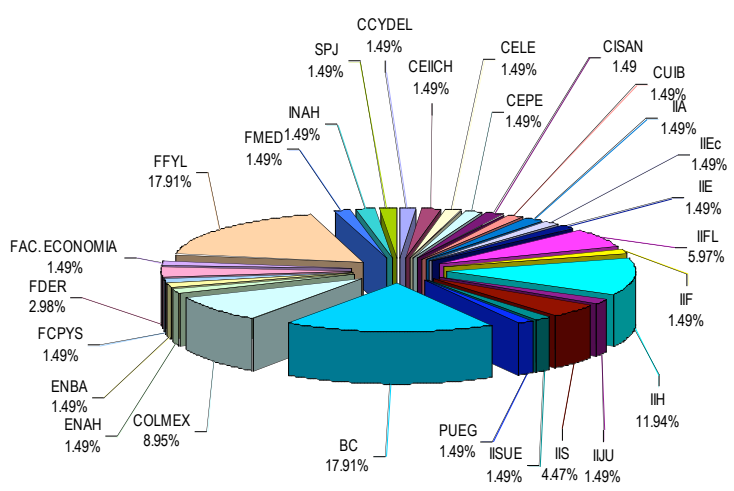

Figura 5. Bibliotecas con las que se tiene un intercambio mayor de préstamo interbibliotecario

En la Figura 5, podemos observar que las bibliotecas del Subsistema de Humanidades, por su especialidad, en gran medida solicitan documentos a otras bibliotecas pertenecientes al mismo Subsistema y a las bibliotecas de las Facultades donde se imparte la especialidad del Centro o Instituto de Investigación, por lo que el convenio de préstamo interbibliotecario anualmente es renovado. De acuerdo a esto, podemos decir que las bibliotecas del Subsistema de Humanidades cuentan con un buen acervo biblio-hemerográfico que cubre aproximadamente el $90 \%$ de las necesidades de información de sus usuarios, por ello, podría existir la posibilidad de que se diera un convenio no de préstamo interbibliotecario, sino de préstamo a domicilio entre ellas.

Cabe mencionar que esto no significa tener que omitir el convenio de préstamo interbibliotecario entre otras bibliotecas fuera del Subsistema de Humanidades.

El servicio de préstamo a domicilio entre estas bibliotecas agilizaría la obtención de documentos entre dichas bibliotecas y posteriormente se podría enlazar a cada una de las bibliotecas de las Facultades donde se imparte la especialidad de cada uno de los centros e institutos de investigación de este Subsistema. 


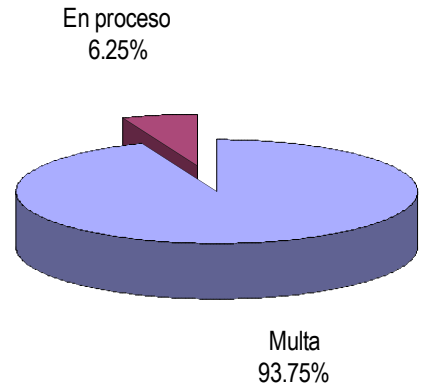

Figura 6. Políticas para la devolución tardía del material

Respecto a la Figura 6, referente a las políticas para la devolución tardía del material bibliográfico, podemos observar que en la mayoría de las bibliotecas del Subsistema, se aplica multa, lo cual ha dado como resultado que sus usuarios sean cumplidos en la devolución o renovación de sus préstamos. La biblioteca que aún no aplica multa para la devolución tardía del material, lleva a cabo una revisión de los usuarios con adeudo de material o con fecha de préstamo vencida, a quienes se les solicita que hagan la devolución o renovación del material.

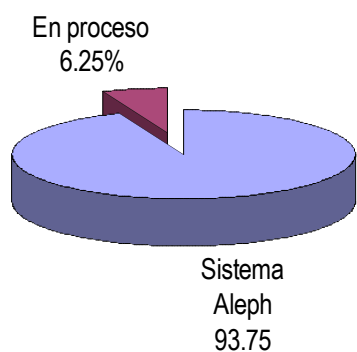

Figura 7. Bibliotecas que utilizan el sistema Aleph para controlar el préstamo a domicilio

La Figura 7, muestra que la mayoría de las bibliotecas del Subsistema cuentan con el sistema ALEPH para controlar el préstamo a domicilio. Éste facilita el control de registro de usuarios, préstamos, devoluciones, renovaciones y reporte de adeudos. Con relación a esto, los coordinadores consideran que la existencia de un sistema único para la automatización del préstamo a domicilio facilitaría un control único de préstamo a domicilio entre estas bibliotecas.

Finalmente, en la Figura 8, podemos ver que, desde el punto de vista de los coordinadores de estas bibliotecas, y dado que la dinámica del préstamo interbibliotecario es mayor entre las mismas bibliotecas del Subsistema, sería ópti- mo establecer no un convenio permanente, sino la posibilidad de una credencial única que garantice el préstamo a domicilio entre las bibliotecas del mismo Subsistema de tal manera que cada persona adscrita a algún Centro o Instituto de tal Subsistema obtenga su credencial única de biblioteca que le permita tener acceso al préstamo a domicilio.

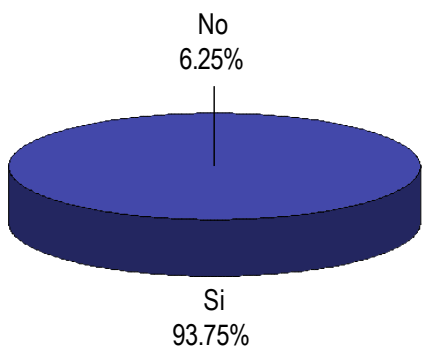

Figura 8. Posibilidad del préstamo a domicilio entre las bibliotecas del Subsistema de Humanidades: según la opinión de los coordinadores de estas bibliotecas

De igual forma los entrevistados estiman que esta modalidad no representaría la contratación de más personal para la atención de servicios al público o la ampliación de sus instalaciones, pues tomemos en cuenta que esta modalidad, por la misma especialidad de cada una de estas bibliotecas, tendría una dinámica parecida al préstamo interbibliotecario.

Esta credencial única permitiría que los usuarios, en cuanto requieran material de alguna de estas bibliotecas, en ese instante pudieran darse de alta y obtener el derecho al préstamo a domicilio. Asimismo es pertinente aclarar que un factor que posibilitaría esta modalidad es que la mayoría cuenta con el sistema Aleph para controlar su préstamo a domicilio, lo cual simplifica una revisión de adeudos.

Por otro lado y como consecuencia, sería necesario un reglamento único para controlar este préstamo, así como también plantearlo a la Comisión de Biblioteca de su Instituto o Centro para que sea aprobada tal modalidad. Consideran que trabajar con el reglamento único, no deberá ser tan complicado, pues la mayoría de las bibliotecas cuentan con su propio reglamento y es aplicado, en buenos términos.

\section{Discusión de los resultados}

De acuerdo con el objetivo de la investigación, analizamos el préstamo interbibliotecario en las bibliotecas del Subsistema de Humanidades de la UNAM, para lograr establecer el préstamo a 
domicilio entre estas bibliotecas, y el diagnóstico que elaboramos es el siguiente:

La mayoría de los investigadores de estas bibliotecas reciben los libros que piden a través de préstamo interbibliotecario en su propia biblioteca, lo que implica que no tienen el hábito de desplazarse a otras bibliotecas. Esta costumbre puede ser una limitante inicial para la aceptación de la propuesta que aquí planteamos. Sin embargo, a pesar de una resistencia inicial, en la práctica esta opción agilizaría el servicio de préstamo para los usuarios de la posible red de las bibliotecas del Subsistema de Humanidades de la UNAM.

Todas las bibliotecas realizan la consulta telefónica para confirmar la disponibilidad del material bibliográfico en otras bibliotecas, así como también realizan la reservación de los documentos. Con respecto a esto consideramos que para la nueva opción esta actividad se podría seguir realizando para que los investigadores acudan con seguridad a la otra biblioteca y obtengan su documento directamente en el área de préstamo, agilizando aún más dicho préstamo.

La mayoría de estas bibliotecas solicitan en mayor porcentaje documentos a otras bibliotecas pertenecientes al mismo Subsistema y a las bibliotecas de las Facultades donde se imparte la especialidad del Centro o Instituto. Al respecto podemos decir que esto hace posible la existencia de una red de préstamo a domicilio entre las bibliotecas del Subsistema y tal vez la incorporación posterior de las Facultades; esto podría contribuir a la existencia de una credencial única de biblioteca no sólo del Subsistema sino que, a futuro, podría ser aprobada para que funcione en toda la red de bibliotecas de la UNAM, tal y como lo planteó el Consejo del Sistema Bibliotecario de la UNAM en el año de 1991.

En la mayoría de las bibliotecas del Subsistema, una de las políticas para la devolución tardía del préstamo a domicilio, es aplicar multa, lo cual ha dado como resultado que aproximadamente los usuarios sean cumplidos en la devolución o renovación de sus préstamos. En este caso podemos decir que la existencia de esta política hace que los investigadores sean conscientes de que el material se ha adquirido especialmente para sus proyectos, pero también para apoyar la docencia, la preservación y la difusión del conocimiento, por ello es necesario hacer notar que también es consultado en préstamo interno por los estudiantes de licenciatura y posgrado, aun cuando están disponibles en los catálogos de las bibliotecas de sus Facultades. Además la mayoría de las bibliotecas cuenta con un regla- mento interno en el que está contemplado el tipo de material que se va a prestar, tiempo del préstamo y sanciones. Esto facilitaría la existencia de un reglamento único.

Todas las bibliotecas del Subsistema cuentan con el sistema ALEPH para controlar el préstamo a domicilio, por lo que consideramos que este sistema no sólo facilitaría un control único de préstamo a domicilio entre las bibliotecas, también permitiría que los usuarios pudieran ver en cada uno de los catálogos de estas bibliotecas si el material está en acervo o prestado, y así puedan agilizar su préstamo sin tener que realizar la consulta telefónica.

\section{Conclusiones}

Tomando en cuenta este panorama, los coordinadores de las bibliotecas del Subsistema de Humanidades opinan que entre sus bibliotecas, es posible eliminar el servicio de préstamo interbibliotecario y establecer una credencial única que permita el acceso al préstamo a domicilio de su material bibliográfico a cada usuario registrado en alguna dependencia del Subsistema, considerando el establecimiento de un reglamento único para controlar el servicio de préstamo a domicilio y para contemplar las políticas del tipo de usuario, tipo de material, tiempo de préstamo y sanciones. Así mismo los coordinadores opinan que su biblioteca es capaz de ofrecer la apertura de sus acervos para la comunidad de Humanidades, permitiendo la posibilidad de crear una Red de préstamo a domicilio en el Subsistema de Humanidades de la UNAM. Esto no quiere decir que se suspendería el servicio de préstamo interbibliotecario para las bibliotecas que no forman parte del Subsistema de Humanidades.

\section{Recomendaciones}

- Invitar a las bibliotecas del Subsistema a crear una red de préstamo a domicilio entre ellas.

- Iniciar una red con la participación de por lo menos dos bibliotecas, permitiendo que poco a poco se incorporen las demás bibliotecas.

- Crear esta red con el propósito de que a futuro se pueda establecer una cooperación bibliotecaria que permita el compartimiento de acervos y recursos.

- Realizar un estudio que permita conocer la opinión de los usuarios acerca de esta nueva opción. 


\section{Referencias}

Azotla, Magdaleno (2002). Poster: dinámica del préstamo interbibliotecario en la biblioteca del Instituto Mora, 2000 - 2001. Estudio bibliométrico. http://biblio.pue.udlap.mx/ congreso/amigos2002/ (2006-11-08)

Busha, Ch (1990). Métodos de investigación en bibliotecología: técnicas e interpretación. México: UNAM, 1990.

Centros de Humanidades. http://dgb.unam.mx/sbusite/ (2007-01-09).

Estructura del sistema bibliotecario. http://www.unam.mx (2007-01-09)

Guerrero, Elda Mónica (1989). El préstamo interbibliotecario y el acceso a los documentos. // Biblioteca Universitaria. 4:1 (Ene/Mar 1989) 4-8.

Herrera, Martha Hilda (2006). Evaluación del servicio de préstamo interbibliotecario de la biblioteca de ciencias biológicas y de la salud del CINVESTAV. México: El autor, 2006. Tesina.

Institutos de Humanidades. http://dgb.unam.mx/sbusite/ (2007-01-09).

Kent, Allen (1980?). Las metas de los recursos compartidos en las bibliotecas. México: ABIESI, 1980?.

López, Ma. Jesús (1996). El préstamo interbibliotecario en España. Madrid: Ministerio de Cultura, 1996.

Martínez, Jaime (1988). El servicio de préstamo interbibliotecario: conceptos, normas y procedimientos aplicables en las bibliotecas de la Universidad Nacional Autónoma de México. México: El autor, 1988. Tesina.

Mattes, Daniel (2000). Cooperación interbibliotecaria internacional: ejemplos actuales y expectativas para el futuro. http://www.dgbiblio.unam.mx/servicios/dgb/publicdgb/ bole/fulltext/vollII1/cooperacion.html (2007-01-27)
Molina, Enrique (1991). Reunión del Consejo del Sistema Bibliotecario de la UNAM. http://www.dgbiblio.unam.mx/ servicios/dgb/publicdgb/bole/fulltext/volVI2/consejo.html (2007-02-20).

Muñoz, Beatriz (1999). El servicio de préstamo interbibliotecario en las bibliotecas médicas http://wotan.liu. edu/dois/data/Papers/juljljah8065.html (2007-02-24).

Quijano, Álvaro (2002). La cooperación y los consorcios en el ámbito mexicano. // Biblioteca Universitaria. Nueva época. 5:22 (Jul/Dic 2002) 103-114.

Reglamento General del Sistema Bibliotecario de la Universidad Nacional Autónoma de México. http://dgb. unam.mx/sbusite/ (2007-01-21)

Seal, Robert A (1990). El proyecto de prueba de préstamo interbibliotecario entre México y los Estados Unidos. // Investigación bibliotecológica. 4:8 (Ene/Jun 1990) 29-30.

Thomson, Sarah Katharine (1970). Inter-library loan involving academia librarie. Chicago: ALA, 1970.

UNAM: bibliotecas. http://www.unam.mx/interna.html?n= $0 \& m=7$ (2007-06-07).

Las referencias se elaboraron con base en las normas siguientes:

ISO690 2a . Ed. 1987-0-1.

Federación Internacional de Asociaciones de Bibliotecarios y Bibliotecas (1994). Pautas para la aplicación de las ISBD a la descripción de partes componentes. [Madrid]: ANABAD: ARCO LIBROS, 1994.

Federación Internacional de Asociaciones de Bibliotecarios e Instituciones Bibliotecarias (1993). ISBD (G): Descripción bibliográfica internacional normalizada general: texto anotado. Madrid: ANABAD: ARCO LIBROS, 1993. 